\title{
Inhaled fluticasone decreases bronchial but not alveolar nitric oxide output in asthma
}

\author{
L. Lehtimäki*,\#, H. Kankaanranta*, , S. Saarelainen ${ }^{\uparrow}$, V. Turjanmaa ${ }^{+}$, E. Moilanen*,\#
}

Inhaled fluticasone decreases bronchial but not alveolar nitric oxide output in asthma. L. Lehtimäki, H. Kankaanranta, S. Saarelainen, V. Turjanmaa, E. Moilanen. (C)ERS Journals Ltd 2001.

ABSTRACT: Exhaled nitric oxide (NO) concentration is a noninvasive measure of airway inflammation and is increased in asthma. Inhaled glucocorticoids decrease exhaled NO concentration, but the relative contributions of alveolar and bronchial levels to the decrease in exhaled NO concentration are unknown. Alveolar NO concentration and bronchial NO flux can be separately approximated by measuring exhaled NO at several exhalation flow rates. The effect of steroid treatment on alveolar and bronchial NO output in asthma was studied.

Alveolar NO concentration and bronchial NO flux were assessed in 16 patients with asthma before and during treatment with inhaled fluticasone for 8 weeks and in 16 healthy controls.

Before the treatment, asthmatics had increased bronchial NO flux (mean \pm SEM: $3.6 \pm 0.4$ versus $\left.0.7 \pm 0.1 \mathrm{~nL} \cdot \mathrm{s}^{-1}, \mathrm{p}<0.001\right)$ but normal alveolar NO concentration (1.2 \pm 0.5 versus $1.0 \pm 0.2$ parts per billion $(\mathrm{ppb}), \mathrm{p}>0.05)$ compared with controls. Inhaled fluticasone decreased bronchial NO flux from $3.6 \pm 0.4$ to $0.7 \pm 0.1 \mathrm{~nL} \cdot \mathrm{s}^{-1}$ $(p<0.01)$ but had no effect on alveolar NO concentration (before: 1.2 \pm 0.5 ; after: $1.2 \pm 0.1 \mathrm{ppb}, \mathrm{p}>0.05)$. The forced expiratory volume in one second improved, whereas asthma symptom score and serum levels of eosinophil cationic protein and eosinophil protein $\mathbf{X}$ decreased during the treatment.

In conclusion, inhaled fluticasone decreases bronchial but not alveolar nitric oxide output simultaneously with clinical improvement in patients with asthma.

Eur Respir J 2001; 18: 635-639.

Nitric oxide (NO) is a gaseous signalling molecule participating in airway physiology. As pulmonary NO production increases in inflammation, the measurement of NO concentration in exhaled air provides a noninvasive method to detect airway inflammation [1, 2]. Patients with an inflammatory airway disease like asthma have increased exhaled NO concentrations [3, 4]. Exhaled NO levels in asthma correlate with the severity of airway inflammation [2]. Treatment with inhaled glucocorticoids reduces increased exhaled NO concentration in asthma towards normal $[5,6]$. Further, bronchial inducible nitric oxide synthase (iNOS) expression [7] and bronchial NO output [8] have been shown to decrease during inhaled corticosteroid treatment. However, it is not known whether the decreased exhaled NO concentration during steroid treatment is explained solely by the decrease in bronchial NO output, or whether steroids also affect alveolar NO output.

Recent mathematical models of pulmonary NO dynamics provide theoretical means to separately assess alveolar and bronchial NO output [8-11]. In these models, the lung is divided into two separate compartments, namely alveolar and bronchial
*The Immunopharmacological Research Group, Medical School, University of Tampere, Depts of ${ }^{\#}$ Clinical Chemistry, Respiratory Medicine and +Clinical Physiology, Tampere University Hospital, Tampere, Finland.

Correspondence: E. Moilanen, Medical School, University of Tampere, Tampere, FIN-33014, Finland.

Fax: 35832158082

Keywords: Asthma eosinophil cationic protein eosinophil protein $\mathrm{X}$ exhaled nitric oxide inflammation

inhaled glucocorticoids

Received: January 182001 Accepted after revision June 122001

The present study was supported by grants from the National Technology Agency (Tekes), Tampere University Hospital Medical Research Fund, Tampere Tuberculosis Foundation and the Academy of Finland. compartments. Air in the alveoli is supposed to have a certain concentration of NO (alveolar NO concentration). During exhalation, the alveolar air travels through the bronchial compartment, where NO diffuses between the bronchial wall and luminal air, and the exhaled air gains its final NO concentration. Because the amount of NO diffusing from the bronchial wall to exhaled air depends on the time that the exhaled air lingers in the bronchial compartment, exhaled NO concentration decreases, whereas NO output (exhaled NO concentration multiplied by exhalation flow rate) increases as a function of exhalation flow rate (fig. 1). Alveolar NO concentration and bronchial NO flux (the quantity of NO diffusing from bronchial wall to luminal air in a unit time) can be calculated by measuring exhaled NO at several exhalation flow rates and then fitting a regression line on the linear part of the NO output curve against exhalation flow rate (flow rate $\left.>50 \mathrm{~mL} \cdot \mathrm{s}^{-1}\right)$. The slope and the intercept of this regression line are approximates of alveolar NO concentration and bronchial NO flux, respectively [9] (fig. 1). Thus, increased bronchial NO flux will cause a higher intercept, whereas increased alveolar NO 


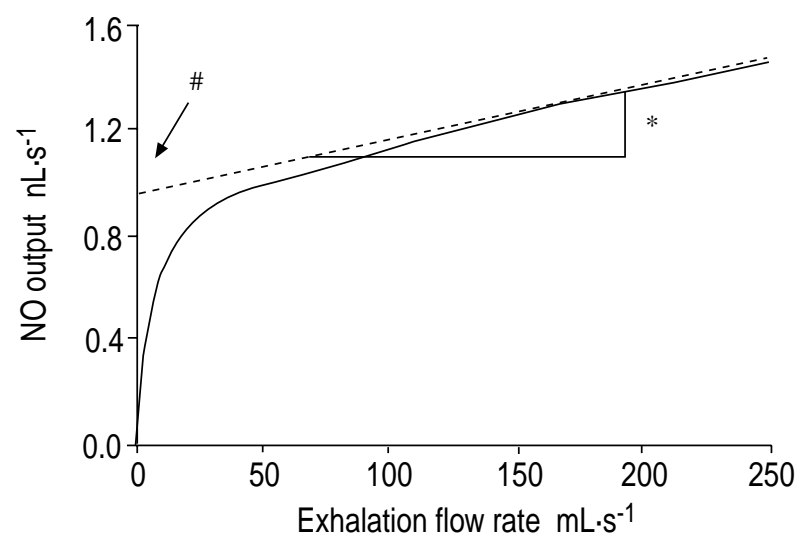

Fig. 1.-Nitric oxide (NO) output $(-)$ against exhalation flow rate and a regression line (- - - -) fitted to the linear part of the NO output curve. The slope $(*)$ and the intercept $(\#)$ of the linear regression are approximates of alveolar NO concentration and bronchial NO flux, respectively [9].

concentration will cause a steeper slope of the regression line. It has previously been shown that this method can be used to differentiate between alveolar and bronchial inflammation, and that NO output in steroid-naive asthma is enhanced in the bronchial but not the alveolar compartment $[12,13]$.

In this study, the bronchial NO flux and alveolar NO concentration was assessed in 16 patients with newly diagnosed asthma before and during treatment with inhaled fluticasone for 8 weeks. The aim of the study was: 1) to assess the effect of inhaled fluticasone on alveolar and bronchial NO output in asthma; 2) to compare the time course of changes in bronchial and alveolar NO output, forced expiratory volume in one second (FEV1) and asthma symptom score during steroid treatment; and 3) to study whether the change in exhaled NO correlates with changes in serum markers of eosinophilic inflammation.

\section{Subjects and methods}

\section{Subjects}

Steroid-naive, nonsmoking patients $(n=16,5$ males, mean age of 36 yrs, range: 20-57) with newly diagnosed asthma were recruited. Asthma diagnosis was based on symptoms and reversible or variable airway obstruction $\left(\beta_{2}\right.$-agonist induced increase in peak expiratory flow (PEF), forced vital capacity (FVC) or $\mathrm{FEV}_{1} \geqslant 15 \%$ or diurnal variability in $\mathrm{PEF} \geqslant 20 \%$ or exercise induced decrease in FEV1 $\geqslant 15 \%$ ). Exhaled $\mathrm{NO}$ was also measured in 16 age- $( \pm 5 \mathrm{yrs})$ and sexmatched nonsmoking healthy controls with no asthmatic symptoms and normal lung function. The study was approved by the ethical committee of Tampere University Hospital and all subjects gave written informed consent.

\section{Study design}

An 8-week, open, follow-up study was conducted. All patients started treatment with inhaled fluticasone propionate (Flixotide Diskus $250 \mu \mathrm{g}$, GlaxoWellcome, Ware, UK) dosed $500 \mu \mathrm{g}$ twice daily during weeks $1-4$, and $250 \mu \mathrm{g}$ twice daily during weeks 5-8. Alveolar NO concentration and bronchial NO flux were assessed, spirometry was measured and patients scored their asthma symptoms on nine occasions: before the treatment and on 8-weekly visits during the follow-up. Serum levels of eosinophil cationic protein (ECP) and eosinophil protein X (EPX) were measured before and after 8 weeks of treatment.

\section{Exhaled nitric oxide and airway function}

Exhaled NO was measured with a Sievers NOA 280® NO analyser (Sievers Instruments, Boulder, CO, USA) at three exhalation flow rates, 100, 175 and $370 \mathrm{~mL} \cdot \mathrm{s}^{-1}$ with a mouth pressure of $9 \mathrm{cmH}_{2} \mathrm{O}$ [12]. The analyser was calibrated daily with a known NO concentration (103 parts per million (ppm), AGA, Sweden) and before every subject with filtered NOfree air. Alveolar NO concentration and bronchial NO flux were calculated for each subject using the method of Tsoukias and George [9]. Airway function was measured with a Vmax $20 \mathrm{C}$ spirometer (SensorMedics, Yorba Linda, CA, USA).

\section{Asthma symptom score}

Asthma symptoms were scored using a written questionnaire. Cough, wheeziness and chest tightness during the past week were each scored as $0=$ none, $1=$ symptoms at 1 day, $2=$ symptoms at $\geqslant 2$ days, $3=$ symptoms every day. Nocturnal asthma symptoms during the past week were scored as $0=$ no nocturnal symptoms, $1=$ symptoms on 1 night, $2=$ symptoms on $\geqslant 2$ nights, $3=$ symptoms every night. Thus, the maximum symptom score was 12 .

\section{Serum markers}

Venous blood was collected into $4 \mathrm{~mL}$ Vacutainer hemogaard SST tubes (Becton Dickinson, Franklin Lakes, NJ, USA) for serum ECP and EPX measurements. The samples were allowed to clot for $60 \mathrm{~min}$ at $22^{\circ} \mathrm{C}$ and then centrifuged at $1,300 \times g$ for $10 \mathrm{~min}$ to separate the serum. Radioimmunoassay (ECP RIA and EPX RIA, Pharmacia AB, Uppsala, Sweden) was used to measure ECP and EPX levels.

\section{Analysis}

Differences in NO levels between patients with asthma and healthy controls were analysed with an unpaired t-test. Changes in NO parameters, lung function and symptom score during the treatment were analysed using repeated measures analysis of variance with Dunnett's post-test. Changes in serum markers were analysed with a paired t-test. Pearson's $r$ was used to study the correlation between changes in different parameters. Results are expressed as mean \pm SEM. 


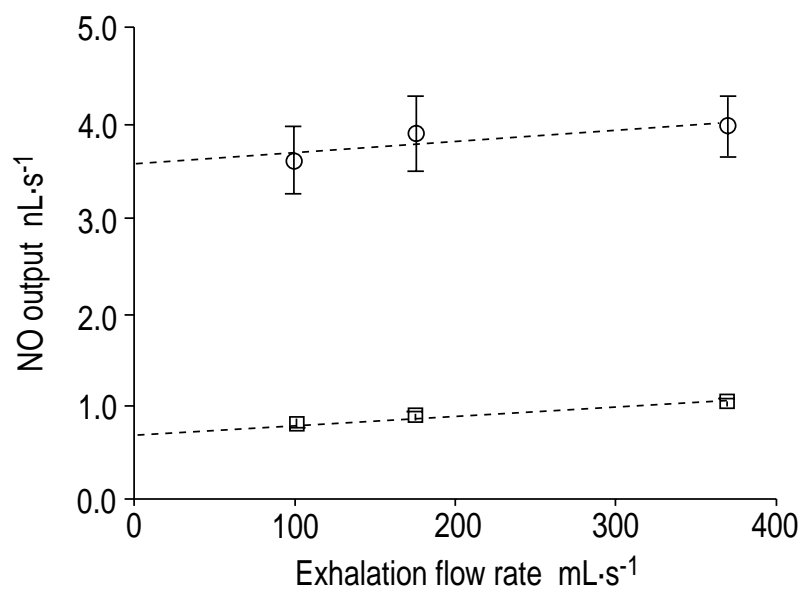

Fig. 2. - Nitric oxide (NO) output (mean \pm SEM) against exhalation flow rate and linear regression in 16 patients with asthma before steroid treatment $(\bigcirc)$ and in 16 healthy controls $(\square)$.

\section{Results}

\section{Bronchial and alveolar nitric oxide}

Before treatment, bronchial NO flux was increased in patients with asthma compared with healthy controls $\left(3.6 \pm 0.4\right.$ versus $\left.0.7 \pm 0.1 \mathrm{~nL} \cdot \mathrm{s}^{-1}, \mathrm{p}<0.001\right)$, while alveolar NO concentration was normal $(1.2 \pm 0.5$ versus $1.0 \pm 0.2$ parts per billion (ppb), $\mathrm{p}>0.05$ ) (fig. 2).
Treatment with inhaled fluticasone for 8 weeks decreased bronchial NO flux in asthmatics from $3.6 \pm 0.4$ to $0.7 \pm 0.1 \mathrm{~nL} \cdot \mathrm{s}^{-1}(\mathrm{p}<0.01)$ and the decrease was significant after 1 week. After treatment, bronchial NO flux in asthmatics was equal to that of healthy controls $(p>0.05)$. The treatment had no effect on alveolar NO concentration (before: $1.2 \pm 0.5 \mathrm{ppb}$, after: $1.2 \pm 0.1 \mathrm{ppb}, \mathrm{p}>0.05$ ) (fig. 3) (table 1).

Forced expiratory volume in one second, asthma symptom score and serum markers

Fluticasone treatment improved FEV1 \% predicted from $85 \% \pm 3 \%$ to $93 \% \pm 4 \%(\mathrm{p}<0.01)$ and the improvement was significant after 2 weeks (fig. 3). There was a trend towards a correlation between the change in bronchial NO flux and the change in FEV1, but this was not significant $(\mathrm{r}=-0.42, \mathrm{p}=0.11)$.

The asthma symptom score decreased from $6.2 \pm 0.9$ to $0.3 \pm 0.2(\mathrm{p}<0.01)$ during the treatment. The time course of symptom score was similar to that of bronchial NO flux. Halving the fluticasone dose after 4 weeks caused no shift in bronchial NO flux, FEV1 or symptom score (fig. 3).

Fluticasone treatment decreased serum levels of ECP from $25 \pm 5$ to $16 \pm 2 \mu \mathrm{g} \cdot \mathrm{L}^{-1} \quad(\mathrm{p}<0.05)$ and EPX from $53 \pm 7$ to $35 \pm 4 \mu \mathrm{g} \cdot \mathrm{L}^{-1}(\mathrm{p}<0.01)$. There was a positive correlation between changes in serum levels of ECP and EPX $(r=0.93, p<0.001)$. There was a trend
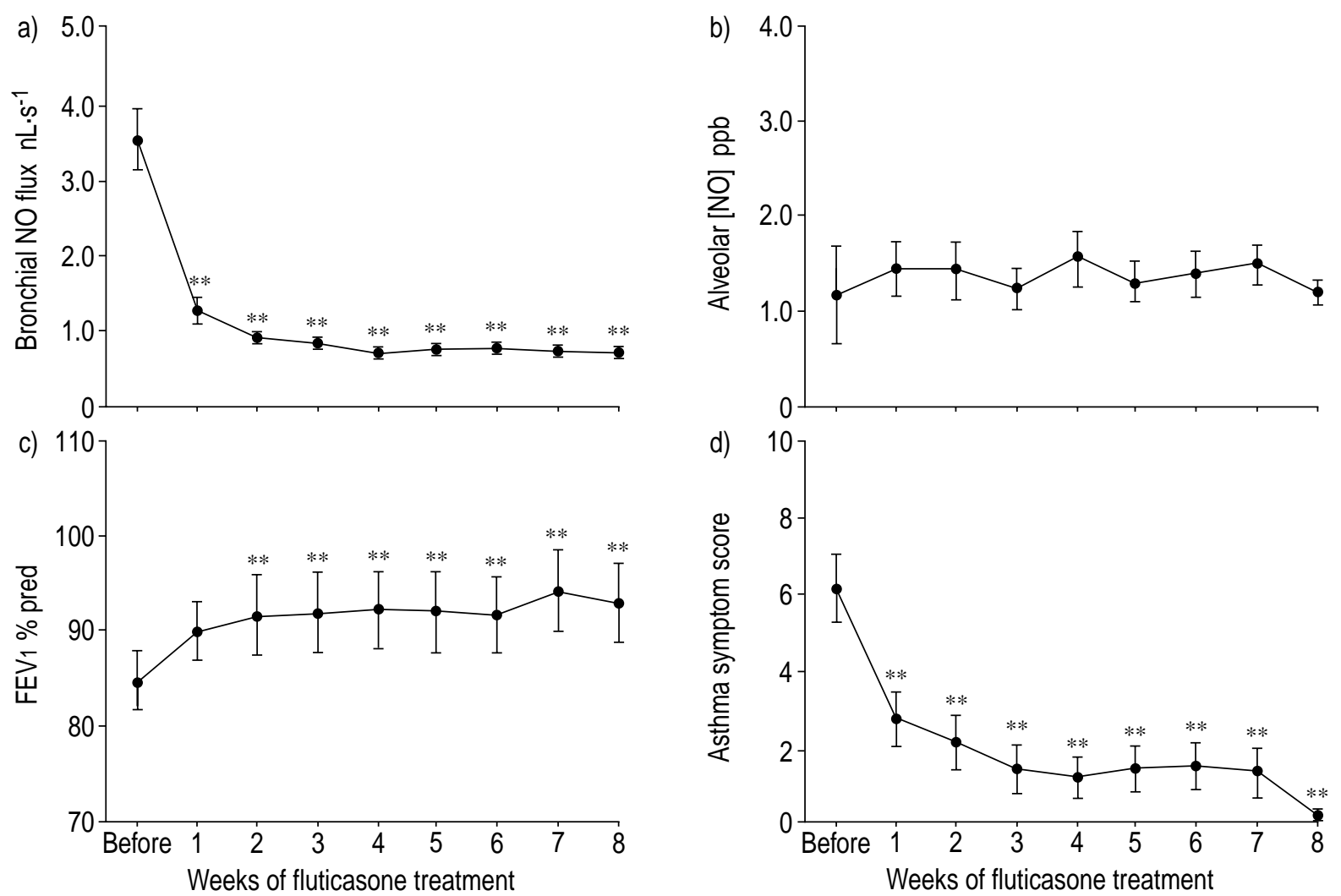

Fig. 3.-a) Bronchial nitric oxide (NO) flux, b) alveolar NO concentration, c) forced expiratory volume in one second per cent of predicted $\left(\mathrm{FEV}_{1} \%\right.$ pred), d) asthma symptom score, before and during 8 weeks of treatment with inhaled fluticasone in 16 patients with newly diagnosed asthma. ppb: parts per billion. ${ }^{* *}: \mathrm{p}<0.01$, compared with baseline value before the treatment. 
Table 1. - Subject characteristics

\begin{tabular}{cccccccccc}
\hline Group & $\mathrm{n}$ & Males n & Age yrs & Steroids & FEV1\% pred & NOBr $\mathrm{nL} \cdot \mathrm{s}^{-1}$ & NOAlv ppb & ECP $\mu \mathrm{g} \cdot \mathrm{L}^{-1}$ & $\mathrm{EPX} \mu \mathrm{g} \cdot \mathrm{L}^{-1}$ \\
\hline Asthma & 16 & 5 & $36 \pm 3$ & Before & $85 \pm 3$ & $3.6 \pm 0.4$ & $1.2 \pm 0.5$ & $25 \pm 5$ & $53 \pm 7$ \\
& & & & After & $93 \pm 4^{* *}$ & $0.7 \pm 0.1^{* * *}$ & $1.2 \pm 0.1$ & $16 \pm 2^{*}$ & $35 \pm 4^{* *}$ \\
Control & 16 & 5 & $37 \pm 3$ & No & $96 \pm 3^{*}$ & $0.7 \pm 0.1^{* * *}$ & $1.0 \pm 0.2$ & $13 \pm 3^{*}$ & $26 \pm 4^{* *}$ \\
\hline
\end{tabular}

Values are expressed as mean \pm SEM. NOBr: bronchial nitric oxide (NO) flux; NOAlv: alveolar NO concentration; ECP: serum level of eosinophil cationic protein; EPX: serum level of eosinophil protein X; FEV1: forced expiratory volume in one second; ppb: parts per billion. $*$ : $\mathrm{p}<0.05$; $^{* *}: \mathrm{p}<0.01 ;{ }^{* *}: \mathrm{p}<0.001$; compared with the asthma group before steroid treatment.

towards a correlation between the change in bronchial NO flux and the change in serum EPX but this was not significant $(\mathrm{r}=0.42, \mathrm{p}=0.11)$.

\section{Discussion}

An increased bronchial NO flux but normal alveolar NO concentration in patients with newly diagnosed asthma was found. Inhaled fluticasone decreased bronchial NO flux but had no effect on alveolar NO concentration. Bronchial NO flux decreased simultaneously with the improvement in lung function and decrease in asthma symptom score and serum markers of eosinophilic inflammation.

The new method of measuring exhaled NO at several exhalation flow rates used in this study, allows differentiation between alveolar and bronchial NO output. The results showing increased bronchial NO flux but normal alveolar NO concentration in steroidnaive asthma are consistent with earlier studies $[12$, 13]. Bronchial epithelial cells express iNOS in response to inflammatory cytokines [14]. Increased exhaled NO concentrations at a single exhalation flow rate in asthma correlate with enhanced iNOS expression in the airways [7]. Thus, the enhanced iNOS expression in asthmatic airways probably explains the increased bronchial NO flux before steroid treatment in patients in the present study.

There are earlier studies showing that inhaled glucocorticoids in asthma decrease exhaled NO measured with the single exhalation flow rate technique $[5,6,15]$. However, with that technique, the anatomical site where steroids reduce NO production cannot be identified. SiLKOFF et al. [8] reported that treatment of asthma with inhaled beclomethasone decreased NO production at the bronchial level, but they did not study whether steroids affect alveolar NO concentration. The present study extends the previous data by showing that inhaled fluticasone decreased bronchial NO flux but had no effect on alveolar NO concentration. As only bronchial NO flux was increased in steroid-naive asthmatics and inhaled glucocorticoids decreased bronchial NO flux but had no effect on alveolar NO concentration, the inflammatory component responsible for increased $\mathrm{NO}$ synthesis in these patients probably mainly affects the conducting airways.

Earlier reports show either weak [16] or no correlation [17] between airway function and concentrations of exhaled NO measured with the singleexhalation flow-rate technique. In this study, a tendency but not a significant correlation between changes in bronchial NO flux and FEV1 during the treatment period was found. These results suggest that exhaled NO is not a marker of airflow limitation in asthma. However, in the group of patients with newly diagnosed asthma, the change in FEV1 and asthma symptoms took place simultaneously with the decrease in bronchial NO flux.

Bronchial NO flux and serum levels of ECP and EPX all decreased during the treatment. The decrease in bronchial NO flux tended to, but did not significantly correlate with changes in serum EPX. It is possible that exhaled NO and these serum markers of eosinophilic inflammation reflect different aspects of asthmatic inflammation. Exhaled NO reflects inflammatory iNOS expression in epithelial and inflammatory cells of airways [7], whereas serum ECP and EPX reflect general eosinophil activation in the body. Thus, exhaled NO is probably a more sensitive marker than serum proteins to detect the anti-inflammatory effects of inhaled glucocorticoids. It has been shown that levels of exhaled NO correlate with numbers of eosinophils in sputum [18], and a better correlation might have been found between changes in bronchial NO flux and measures of local eosinophil activation in the lungs.

Inhaled glucocorticoids have been shown to reduce iNOS expression in asthmatic airways [7]. Steroids may reduce iNOS expression indirectly by suppressing asthmatic airway inflammation and thus, downregulating the synthesis of pro-inflammatory cytokines known to induce iNOS expression. Glucocorticoids can also reduce iNOS expression directly by inhibiting nuclear factor- $\kappa \mathrm{B}$, a critical factor for transcription of iNOS [19, 20]. However, the detailed mechanism of how inhaled glucocorticoids reduce NO production in the airways, and whether the decrease in bronchial NO flux contributes to the anti-inflammatory action of inhaled glucocorticoids still needs to be determined.

In conclusion, inhaled fluticasone in patients with newly diagnosed asthma had no effect on alveolar nitric oxide concentration but decreased bronchial nitric oxide flux simultaneously with clinical improvement and a decrease in serum markers of eosinophilic inflammation.

Acknowledgements. The authors would like to thank P. Pirttimäki and M-L. Lampén for their skillful assistance with measurements of exhaled nitric oxide and serum markers. 


\section{References}

1. Silkoff PE. Noninvasive measurement of airway inflammation using exhaled nitric oxide and induced sputum. Clin Chest Med 2000; 21: 345-360.

2. Kharitonov SA, Barnes PJ. Clinical aspects of exhaled nitric oxide. Eur Respir J 2000; 16: 781-792.

3. Alving K, Weitzberg E, Lundberg JM. Increased amount of nitric oxide in exhaled air of asthmatics. Eur Respir J 1993; 6: 1368-1370.

4. Kharitonov SA, Yates D, Robbins RA, LoganSinclair R, Shinebourne EA, Barnes PJ. Increased nitric oxide in exhaled air of asthmatic patients. Lancet 1994; 343: 133-135.

5. Kharitonov SA, Yates DH, Barnes PJ. Inhaled glucocorticoids decrease nitric oxide in exhaled air of asthmatic patients. Am J Respir Crit Care Med 1996; 153: 454-457.

6. van Rensen EJ, Straathof KM, Veselic-Charvat MA, Zwinderman AH, Bel EH, Sterk PJ. Effect of inhaled steroids on airway hyperresponsiveness, sputum eosinophils, and exhaled nitric oxide levels in patients with asthma. Thorax 1999; 54: 403-408.

7. Saleh D, Ernst P, Lim S, Barnes PJ, Giaid A. Increased formation of the potent oxidant peroxynitrite in the airways of asthmatic patients is associated with induction of nitric oxide synthase: effect of inhaled glucocorticoid. FASEB J 1998; 12: 929-937.

8. Silkoff PE, Sylvester JT, Zamel N, Permutt S. Airway nitric oxide diffusion in asthma: Role in pulmonary function and bronchial responsiveness. Am J Respir Crit Care Med 2000; 161: 1218-1228.

9. Tsoukias NM, George SC. A two-compartment model of pulmonary nitric oxide exchange dynamics. $J$ Appl Physiol 1998; 85: 653-666.

10. Högman M, Drca N, Ehrstedt C, Meriläinen P. Exhaled nitric oxide partitioned into alveolar, lower airways and nasal contributions. Respir Med 2000; 94: 985-991.

11. Jörres RA. Modelling the production of nitric oxide within the human airways. Eur Respir $J$ 2000; 16: 555-560.

12. Lehtimäki L, Turjanmaa V, Kankaanranta $\mathrm{H}$, Saarelainen S, Hahtola P, Moilanen E. Increased bronchial nitric oxide production in patients with asthma measured with a novel method of different exhalation flow rates. Ann Med 2000; 32: 417-423.

13. Lehtimäki L, Kankaanranta $\mathrm{H}$, Saarelainen $\mathrm{S}$, et al. Extended exhaled NO measurement differentiates between alveolar and bronchial inflammation. Am J Respir Crit Care Med 2001; 163: 1557-1561.

14. Hamid Q, Springall DR, Riveros-Moreno V, et al. Induction of nitric oxide synthase in asthma. Lancet 1993; 342: 1510-1513.

15. Jatakanon A, Kharitonov S, Lim S, Barnes PJ. Effect of differing doses of inhaled budesonide on markers of airway inflammation in patients with mild asthma. Thorax 1999; 54: 108-114.

16. Sippel JM, Holden WE, Illes SA, et al. Exhaled nitric oxide levels correlate with measures of disease control in asthma. J Allergy Clin Immunol 2000; 106: 645-650.

17. Ho L-P, Wood FT, Robson A, Innes JA, Greening AP. Atopy influences exhaled nitric oxide levels in adult asthmatics. Chest 2000; 118: 1327-1331.

18. Jatakanon A, Lim S, Kharitonov SA, Chung KF, Barnes PJ. Correlation between exhaled nitric oxide, sputum eosinophils, and methacholine responsiveness in patients with mild asthma. Thorax 1998; 53: 91-95.

19. Kleinert H, Euchenhofer C, Ihrig-Biedert I, Forstermann U. Glucocorticoids inhibit the induction of nitric oxide synthase II by down-regulating cytokineinduced activity of transcription factor nuclear factor-kappa B. Mol Pharmacol 1996; 49: 15-21.

20. Moilanen E, Whittle BRJ, Moncada S. Nitric oxide as a factor in inflammation. In: Gallin JI, Snyderman S, Fearon DT, Hayes BF, Nathan C, eds. Inflammation: Basic Principles and Clinical Correlates. Philadelphia, Williams \& Wilkins, 1999; pp. 787-801. 